\title{
Sophisticated Thinking: Higher Order Thinking Skills
}

\author{
Elena Tikhonova \\ Peoples' Friendship University of Russia \\ Correspondence concerning this article should be addressed to Elena Tikhonova, Department of Foreign \\ Languages, Peoples' Friendship University of Russia, 3/379 Ordzhonikidze Street, Moscow, Russian \\ Federation, 115419. E-mail: etihonova@gmail.com
}

\section{Natalia Kudinova \\ National Research University Higher School of Economics}

\begin{abstract}
Correspondence concerning this article should be addressed to Natalia A. Kudinova, English Language Department for Economic and Mathematical Disciplines, National Research University Higher School of Economics, 26 Shabolovka St., Moscow, Russian Federation, 119049. E-mail: kudinova.natalie@gmail.com
\end{abstract}

\begin{abstract}
The information-based society determines that the key factor to achieve success is the development of sophisticated thinking. That said, the thinking process cannot be just a mere imitation of cognitive work, since the digital age requires the authentic skills of working with a flow of information that is being constantly updated. This paper deals with the last stage of the study devoted to the development of sophisticated thinking. It focuses on the enhancement of higher order thinking skills. We claim that the cognitive processes should be based on three phases: development of disposition towards both thinking process and processed information; development of lower order thinking skills which serves as an indispensable basis for developing higher order thinking skills; and development of higher order thinking skills. The omission or reordering of any of these phases may result in significant deterioration of the obtained results. The special emphasis is put on the idea that higher order thinking skills are more effectively developed when lower order thinking skills have already been interiorized. Furthermore, the development of disposition is regarded as the cornerstone of the development of sophisticated thinking in general. Also, due to its defining feature of polysemy, a literary text is considered to be the most appropriate basis for enhancing students' thinking skills. For the purpose of verifying the theoretical ideas, a qualitative study has been conducted. The two groups of students, who participated in the first and second stages (three-month cycle each) of our project, continue to be involved in this one. They are second-year bachelor students of the Higher School of Economics who are studying English as a second language. On the basis of the ideas expressed by B. Bloom about the division between lower and higher order thinking skills and by J. Mezirow about transformative learning we designed tasks to enhance higher order thinking skills. These tasks were related to the short stories written by D. Barthelme and printed as a collection, Sixty Stories. To teach the students of both groups (control and experimental), the textbased approach with special techniques to measure the students' level of understanding and the ability to apply the given information was used. The results of the experiment indicated that the students of both groups made headway in their application of thinking skills. However, the students of the experimental group demonstrated a more significant shift due to the fact that the development of their disposition towards cognitive processes and processed information had been specifically targeted over the course of the first and second stages of the project. Another important outcome of the study was that the participants' frame of reference was extended which allows us to speculate that the development of sophisticated thinking may result in the change of a person's interpretation of socio-cultural situation. Hence, a further in-depth study of the issue should be conducted.
\end{abstract}

Keywords: lower order thinking skills, higher order thinking skills, sophisticated thinking, transformative learning, frame of reference, revised Bloom's taxonomy

The last 20 years have brought about more pedagogical change than the last several centuries taken together, made possible, in part, due to the rapid development of technology, especially the Internet. The invention of the Internet gave birth to a new type of society, a new era - the Information Age - which 
is characterized, among other things, by vast amounts of information now accessible to a person irrespective of where they are thanks to different kinds of gadgets. The information age sets new requirements for educators, the most urgent of which is the ability to work with available information. Now a person's success in life "lies in being able to communicate, share, and use information to solve complex problems, in being able to adapt and innovate in response to new demands and changing circumstances, in being able to marshal and expand the power of technology to create new knowledge, and in expanding human capacity and productivity" (Binkley et al., 2012). This means that there is a significant shift in the educational paradigm that leads to teachers focusing more on the development of skills, known as the 21st century skills: creativity and innovation, critical thinking and metacognition, collaboration and communication, information and media literacy, motivation and leadership, social and cross-cultural skills, etc. Over the last several decades, the particular focus has been on the development of critical thinking, which, as one of the higher order skills, has been considered a core learning outcome required for university students to succeed in modern information-based society, and to satisfy the demands of the 21st century workforce. Consequently, much research is currently devoted to finding the optimum techniques to foster critical thinking along with other higher order thinking skills (HOTS) among high school and college or university students.

However,young people do not seem to be particularly receptive to new approaches in teaching. From our experience of working in different universities, we can say that youth today are still struggling with applying HOTS. Despite all the efforts of their teachers, students do not readily develop HOTS. Instead, they tend to imitate cognitive work by just copying someone else's ideas and referring to these as their own.

We believe the underlying problem here is that educators strive to develop students' HOTS while completely ignoring their lower order thinking skills (LOTS). LOTS, often referred to as the recall skills, deal with new knowledge and knowledge that a person already has, and include such skills as memorizing, recalling, and understanding. Nowadays, young people appear to be reluctant and unable to memorize information or try to comprehend it, as they do not see the point of doing so. They can easily access this information online from wherever they are and whenever they need it thanks to new technologies that are versatile and portable. Such a tendency seems to cause LOTS to degrade which may lead to students' inability to develop HOTS. We claim that LOTS, being simple cognitive processes, are the basis for the more complex and enhanced ones (Tikhonova,
Kudinova, 2015). Thus, we think HOTS and LOTS are interconnected: "The more proficient you are at 'lower-order' skills, the more proficient you can become at higher order skills" (Lemov, 2010).

In our view, students should not be taught HOTS and LOTS separately, but rather a particular approach that combines both HOTS and LOTS, one we call 'sophisticated thinking'. In Sophisticated Thinking: Lower Order Thinking Skills, sophisticated thinking is defined as "a balanced combination of welldeveloped lower order and higher order thinking skills where LOTS become interiorized and do not hinder the development of HOTS" (Tikhonova, Kudinova, Golubovskaya, 2015, pp. 5461-5470). In many ways it echoes Presseisen's idea about the transition from "simple to more complex operations, from observable to abstract dimensions, and from an emphasis on working with known materials toward an emphasis on creating or inventing new, previously unknown approaches or materials" (Presseisen, 2001, pp. 47-53). The very notion of sophisticated thinking emphasizes the equal importance of LOTS and HOTS and will enable teachers to pay an equal amount of attention to the development of both sets of skills.

The early results of our recent three-stage project have prompted our view that the optimal way to develop sophisticated thinking involves three overlapping phases in which all sets of skills are continually being developed while a certain skill is in focus during each particular phase. The first phase presupposes the development of students' disposition towards the text and, more broadly, towards cognitive work itself. According to D. F. Halpern's approach, critical thinking is both a learned collection of cognitive skills and a disposition towards engaging in the reasoning process (Halpern, 2003); extending this view, we argue that the same applies to sophisticated thinking. As the first and second stages of our study indicated, students with an established disposition towards the thinking process demonstrated a more significant shift in the development of their cognitive processes than students without one. The second phase refers to enhancing LOTS, the reasons for which have been stated above. The third phase involves the development of HOTS the subject of the current paper. These results indicate that a certain kind of algorithm should be used to facilitate sophisticated thinking in students.

Over the first stage of the study, the text emerged as a main constituent of this process, essential in developing sophisticated thinking skills. However, not just any text can be used as a facilitator. Our findings indicate that a literary text is the best type as it uses literary language characterized by polysemy, that is, by multiple meanings. The ability of a literary text to produce multiple meanings makes it possible to have different levels of understanding and interpretations 
of one text, and so to "extend the text beyond its apparent surface" (Luberda, 1998). Tikhonova et al. signal that to go beyond the surface and unfold deeper levels of a text, one has to acquire critical thinking skills (as well as sophisticated thinking skills), and that such textual work simultaneously serves as a springboard for developing those skills (2015, pp. 5461-5470). For the purposes of this study, the texts chosen were: Pelican Brief by John Grisham, Runaway, a collection of short stories by Alice Munro, and short stories from the collection Sixty Stories by Donald Barthelme.

\section{Materials and Methods}

\section{Taxonomy of Cognitive Domain}

The theoretical framework of the project relies on the taxonomy suggested by Benjamin S. Bloom in the 1950s and revised later on by Lorin W. Anderson and David R. Krathwohl. The latter singled out the following categories in Bloom's taxonomy:

1. 'Remember', which means retrieving relevant knowledge from long-term memory: (1) Recognizing (2) Recalling

2. 'Understand', which refers to determining the meaning of instructional messages, including oral, written, and graphic communication: (1) Interpreting (2) Exemplifying (3) Classifying (4) Summarizing (5) Inferring (6) Comparing (7) Explaining

3. 'Apply', which involves carrying out or using a procedure in a given situation: (1) Executing (2) Implementing

4. 'Analyze', which represents the idea of breaking material into its constituent parts and detecting how the parts relate to one another and to the overall structure or purpose: (1) Differentiating (2) Organizing (3) Attributing

5. 'Evaluate', which presupposes making judgments based on criteria and standards: (1) Checking (2) Critiquing

6. 'Create', which stands for putting elements together to form a novel, coherent whole or making an original product: (1) Generating (2) Planning (3) Producing (Krathwohl, 2002, pp. 212-218).

The first three categories (Remember, Understand and Apply) are traditionally considered LOTS and the last three (Analyze, Evaluate, Create) are HOTS; the latter is the explicit focus of this paper.

We find Anderson and Krathwohl's version of the system to be most appropriate, as it offers a less rigid hierarchy than the original one, allowing us to regard the 'Analyze', 'Evaluate' and 'Create' categories as having the same level of difficulty and as being overlapping and interacting functions. This, in turn, means that exercises designed to develop those skills should aim at targeting them, not individually, but as a complex entity that needs to be enhanced as a whole.

\section{Transformative Learning}

The theory of transformative learning was proposed by Jack Mezirow in the 1970s and describes how learners construe, validate, and reformulate the meaning of their experience (Cranton, 1994). One of its central tenets is the concept of perspective transformation that explains how adults revise their meaning structures, which are viewed as frames of reference that are based on "the totality of individuals' cultural and contextual experiences and that influence how they behave and interpret events" (Taylor, 1998). According to E. Taylor, these frames of reference function as filters that interpret and give meaning to a new experience which a person comes upon. They either reinforce the existing perspective or, if an experience is radically different, incongruent and cannot be assimilated into the existing view, reject it or they themselves are transformed to accommodate the experience (Taylor, 1998).

Mezirow distinguishes ten phases of perspective transformation:

Phase 1. A disorienting dilemma

Phase 2. A self-examination with feelings of guilt or shame

Phase 3. A critical assessment of epistemic, sociocultural, or psychic assumptions

Phase 4. Recognition that one's discontent and the process of transformation are shared and that others have negotiated a similar change

Phase 5. Exploration of options for new roles, relationships, and actions

Phase 6. Planning of a course of action

Phase 7. Acquisition of knowledge and skills for implementing one's plans

Phase 8. Provisional trying of new roles

Phase 9. Building of competence and self-confidence in new roles and relationships

Phase 10. A reintegration into one's life on the basis of conditions dictated by one's perspective (Kitchenham, 2008, pp. 104-123).

In On Critical Reflection, Mezirow argued that "learning to think for oneself involves becoming critically reflective of assumptions and participating in discourse to validate beliefs, intentions, values and feelings"(Mezirow, 1998,pp.185-198). The significance of this approach cannot be underestimated, especially today in the digital age. In 1998, the same year, Susan 
Imel stated that "transformative learning may not always be a goal of adult education, but its importance should not be overlooked and all adult educators should strive to understand it, even if they do not choose to foster it" (Imel, 1998).

Although Mezirow's model is aimed at the process of learning as it is, we believe it can help gain significant results in achieving more specific objectives. Our own research framework seeks to adapt the aforementioned model to find the optimal way of developing HOTS using literary texts as a basis:

Phase 1. A dilemma as a starting point of a thinking process. A dilemma appears when a student is asked a question that does not have an immediate and ready-made answer in the text. Such a question often deals with issues connected with character's actions, their underlying motives, symbolism, etc.

Phase 2. A critical assessment of pre-existing epistemic and sociocultural assumptions about the problem raised.

Phase 3. Recognition that one's discontent and the process of transformation are shared, and that others have negotiated a similar change

Phase 4. Exploration of options for new relationships, solutions, and explanations

Phase 5. Acquisition of new thinking techniques and skills

Phase 6. Provisional trying of new techniques and skills

Phase 7. Building of competence and self-confidence in new techniques and skills

Phase 8. An integration of new thinking techniques and skills into one's way of thinking on the basis of different texts students are exposed to over the course of their study

This revised model allows enhancing HOTS as a complex entity since Analyze, Evaluate and Create skills are being developed simultaneously. However, it is vital to point out that none of these skills can be cultivated without highly-developed LOTS: Remember, Understand, and Apply skills.

\section{Results}

\section{Overview of the First and Second Stages}

The current paper is devoted to the description of the third stage of the project begun on 1 September 2014, in Moscow, Russia. Each stage lasted about three months. The results of the first and second stages are described in Sophisticated Thinking: Text, Task and
Situation (Tikhonova, Kudinova, Golubovskaya, 2015, pp. 5461-5470) and Sophisticated Thinking: Lower Order Thinking Skills (Tikhonova, Kudinova, 2015) respectively.

The theoretical basis of the first stage of the project drew on D. F.Halpern's approach to critical thinking according to which critical thinking is not a by-product of standard instruction in a content area, and gaining positive effects is possible only through systematic educational effort (Halpern, 2003). Furthermore, Halpern claims that critical thinking is both a learned collection of cognitive skills and a disposition towards engaging in the reasoning process. As previously mentioned, the study was connected with literary texts, which provide opportunities for reflection and broad analysis.

The underlying idea of the first research phase was that critical thinking skills can be developed and transferred via embedded instruction in language education. 80 students (38 female and 42 male, aged 18) willingly and enthusiastically participated in all the stages of the project. The participants (secondyear bachelor students studying at the National Research University Higher School of Economics at the $\mathrm{C} 1$ level of English in the CEFR for languages) were randomly divided into two groups. The first group received critical thinking instructions embedded in a system of tasks related to their reading of the thriller by J. Grisham, "The Pelican Brief”. The second group, the control group, did not receive similar instructions; instead, they were taught within the frameworks of the communicative approach without reading "The Pelican Brief" (Tikhonova, Kudinova, Golubovskaya, 2015, pp. 5461-5470).

To establish the level of critical thinking development of the participants, a pre-test based on Watson-Glaser Critical Thinking Appraisal (W-GCTA) (W-GCTA, 2012) was conducted at the outset of the study. Next, both groups took part in a subsession course consisting of 24 lessons, after which the posttest (W-GCTA) was used to assess the influence of the techniques used on the level of critical thinking skills of participants. The procedure was repeated at each stage, with the post-test of the previous stage being used as the pre-test for the next stage.

A shift towards the improvement of critical thinking skills emerged during this stage of the experiment. The students from group one demonstrated a change in their disposition towards critical thinking and processing information, although this was not dramatic due to the short time period of the study (three months). Noteworthy, however, is that participants changed their disposition not only to the process of reasoning, but also to the process of processing information. This result led us to the conclusion that a persuasive-axiological component of critical thinking 
includes attitude to both critical thinking itself and the processed information as well.

During the course of the study, we observed that participants encountered problems while attempting to work with the cognitive component of critical thinking due to their lack of certain skills. For example, when trying to analyze the text (the instance of higher order thinking) they struggled to identify the necessary textual parts, to infer meaning from the context, and other instances of lower order thinking skills. Moreover, students' inability to memorize information which they came across repeatedly suggested an underlying belief that remembering was a simple operation that can be done quickly if the need be. In addition, the students tended to regard reproduction of somebody else's point of view as a thinking process on account that this idea seemed reasonable to them. They did not even try to think it over by themselves (Tikhonova, Kudinova, 2015). Thus, this situation made us suppose that developing LOTS as an indispensable basis of sophisticated thinking will (a) enable the participants to regard the thinking process as a process in itself but not as the reproduction of someone else's ideas; (b) determine the development of critical thinking as well. These notions helped shape the theoretical basis of the second stage of the study.

The second stage dealt with Boom's taxonomy in its amended form by Lorin W. Anderson and David R. Krathwohl. The choice was made in favor of the latter, since this model provides a more flexible system of cognitive categories which, in their turn, can be divided respectively into LOTS and HOTS. However, we claimed the relevance of developing LOTS and HOTS as equally important and overlapping since they constitute a particular type of thinking, sophisticated thinking, as defined above. Another change was introduced into the methodology of the project. The first-stage control group, whose disposition to critical thinking had not changed according to the results of the first stage became involved in the same activities as the experimental group; this methodoglical change was carried out in order to see the influence of disposition on the way the participants regarded the material, on their willingness to work with it, and on the development of LOTS.

For the purpose of the second stage of our project all participants worked with the collection of short stories Runaway by Alice Munro. These stories were chosen as a textual basis because they are mainly devoted to interpersonal relationships and the inner struggles of women, subjects which traditionally appeal more to female readers rather than to men. Since participants in the experimental group were predominantly male, the choice of textual input was also an opportunity to confirm or refute our hypothesis about the role disposition plays in thinking skills development.
At the end of the second stage of the study, the experimental group exhibited more interest in working with a literary text, while the students of the control group, though divided into different subgroups depending on the development of their critical thinking skills after the learning session, displayed less interest in the text and were more unwilling to do the tasks aimed at the 'Remember' category. Moreover, due to a more developed disposition to the cognitive process, the male students of the experimental group took the same interest in the stories as their female counterparts, while the male students in the control group stressed that the stories were more suitable for girls. The experimental group participants were inclined to extract information from the text whereas the control group tended to work with the factual information, which did not involve much of the thinking process.

At this three-month stage, we managed to gain a significant shift in the participants' disposition towards the process of thinking, showing them that the cognitive process involved in simple operations seemingly unrelated to textual analysis was, in fact, an indispensable part of thinking. The results of the experiment seem to confirm that HOTS without welldeveloped LOTS are more likely to be a mere imitation of a thinking process and reproduction of someone else's viewpoint; this in turn suggests that it is vital to encourage students to do more detailed work with the information provided (Tikhonova, Kudinova, 2015).

\section{Design of the Third Stage Hypothesis}

The first hypothesis is that well-developed disposition towards the cognitive work and wellenhanced LOTS will enable HOTS to be developed in a fast and optimal way. The balance between LOTS and HOTS, which constitutes sophisticated thinking, will not allow participants to avoid cognitive work and to resort to copying someone else's thoughts since the participants may find it much easier to do analysis by themselves and form their own reasoned opinions. The second hypothesis is that the students from the control group will show a significant shift in the development of HOTS, but the shift will be less than that of the experimental group as the disposition towards the process of thinking was previously developed among the students of the experimental group.

\section{Participants and Procedure}

The third stage of the study was also conducted at the National Research University Higher School of Economics with the same number of participants (80 
students: 38 female, 42 male) who are second year students at C1 English level, aged 18-19.

Similar to the first and second stages, the purpose and the nature of the study were explained to those participating. The division of the groups (control and experimental) remained the same as well. The students were given instructions of HOTS development embedded in a system of tasks related to the collection of short stories Sixty Stories by Donald Barthelme. In this paper, the short story The School serves as an example of the kinds of exercises the students were set.

The third stage of the study includes three sessions: (1) learning session (subdivided into 24 subsessions due to the number of language classes twice a week during the three month-period); (2) post-test (W-GCTA); (3) post-study questionnaire. The results of W-GCTA of the second stage serve as the pre-test for the third stage of the experimen.

\section{Learning Session}

Both groups took part in a twenty-four-subsession course. The sessions were similar in pedagogical components and duration. For each session the students were to read a part of a story or, if a story was short enough (e.g., The School), the whole story, and do a set of pre- and while-reading activities. Afterreading tasks were completed in class. All sets of tasks were designed according to the categories of Anderson and Krathwohl's taxonomy. Due to the format of this paper and the space available, we provide a selection of examples of tasks based on the short story The School. It is relevant to once again signal that we strongly believe in the relativity of differentiating between the Analyze, Evaluate and Create categories as well as LOTS. Thus, most tasks have overlapping aims (ranging from the Remember to Create category) with a dominant one.

1. The tasks with the predominant aim to develop thinking skills that relate to the Analyze category which refers to breaking material into its constituent parts and detecting how the parts relate to one another and to the overall structure or purpose. Using graphic or visual organisers may serve as a useful tool to develop these skills: enabling students to fully focus on making connections, finding meaningful patterns, organizing the information found in the text or personally reacting to its content (Richardson, 2013). In our study we used story maps. In class the students were asked to fill out a chart. See the type of story map used below.

However, it is vital to point out that we did not expect a unified representation of information. The completed flowchart story maps varied in such categories as Time, Characters, Problem/Conflict, order and number of Events, Resolution/End according to students' responses. See Appendix 1 for examples of the participants' work [Appendix A, Appendix B].

As a follow-up to the flowchart story map activity, participants were also asked to comment on the order of the events. Preparing why-questions for their partners to answer might actively engage students in

\begin{tabular}{|c|}
\hline $\begin{array}{c}\text { Setting } \\
\text { Place: } \\
\text { Time: }\end{array}$ \\
\hline Problem / Conflict \\
\hline Characters \\
\hline Plot \\
Event 1 \\
Event 2 \\
Event 3 \\
\hline | \\
\hline Resolution / End \\
\hline
\end{tabular}

Figure 1. Flowchart story map.

thinking over the text and its content. This task might also encourage students to see the problematic issues raised in the stories, as well as how these might serve as a springboard for further in-depth class discussion and a transition towards subsequent categories, such as Evaluation or even Creation. We define Whyquestions as questions that require students to look into the motifs, symbolism, or possible development of a plotline. A few examples of the participants' questions include:

- Why were the events organized in this particular order?

- What was the purpose of giving shoolchildren a chance to sound as philosophy scholars?

- What does the appearance of a new gerbil at the end of the story stand for?

- What will happen to the new gerbil?

- What did the school teach the children?

- What does the title of the story mean?

2 . The tasks with the predominant aim to develop thinking skills that relate to the Evaluate category, which involves making judgments based on criteria and standards. First, this involved the students answering Why-questions prepared by a teacher. Some examples include:

- Can you determine the role of the teacher in the story?

- What does the teacher in the short story symbolize? 
- Why did Helen kiss the teacher?

- Why does the story use first-person narration?

Next, this entailed students answering Whyquestions prepared by fellow students similar to those listed above. Finally, - this involved commenting upon a quotation from the text through an in-depth analysis and evaluation of what was said in terms of the story and going beyond its limits. Examples include the following:

- Comment upon the following quotation. Explain what is meant and whether you agree with it or not and why. "And they said, is death that which gives meaning to life? And I said no, life is that which gives meaning to life" (Barthelme, 2003, pp. 304-308).

3. The tasks with the predominant aim to develop thinking skills that relate to the Create category, which presupposes putting elements together to form a novel, coherent whole or making an original product. One such task, writing an essay, is believed to consolidate students' ideas and thoughts, to enable them to think more thoroughly about a problem, in general going beyond the limits of the story, and engage in-class discussions by appealing to students' real-life experience and exploring it from a different perspective. Some suggested essay topics include:

- How much value does school have in the modern society?

- What gives meaning to life? To your life?

- Which role do you think a teacher is supposed to play: a guide on the side or a sage on the stage?

Another similar task to promote thinking process involves writing the continuation of the story or rewriting a story according to students' own notions of what it should be in order to convey the ideas and conclusions they have arrived at while working with the text.

\section{Interpretation of the Pre- and Post-Test W-GCTA Scores}

The Watson-Glaser Critical Thinking Appraisal (40item paper and pencil) psychometric test of critical thinking and reasoning was selected as a measurement tool of critical thinking skills, their depth and quality. The five subtests of the test (inference; recognition of assumptions; deduction; interpretation; evaluation of arguments) require different, though interdependent, applications of analytical reasoning in a verbal context with scores reported on three subscales (W-GCTA, 2012). The final score of each participant is the sum of all correct answers to the items of the paper (from 1 to 40 on the five subtests). The scores are graded through the following categories:

A - Well above average performance, $91 \%$ and above
B - Above average performance, $71-90 \%$

C - Average, 31- 70\%

D - Below average performance, $11-30 \%$

E - Well below average performance, $10 \%$ and below

Table 1 below illustrates the overall performance at the second stage for students in the experimental group. $85 \%$ of them demonstrated an average critical thinking ability, $5 \%$ a below average thinking ability, and only $10 \%$ an above average thinking ability.

By comparison, Table 2 below illustrates that 82 $\%$ of participants in the control group demonstrated average critical thinking abilities, $15 \%$ a below average performance, and $2.5 \%$ an above average ability.

Following the learning session of the third stage, the repeated W-GCTA test was used to measure the achievements of the participants, with each participant receiving a new test with different scenarios. Recommendations on how to work with the test were given. Tables 3 and 4 below illustrate these results for both groups.

In the experimental group, two students from subgroup D moved to subgroup C; moreover, 6 students from subgroup $\mathrm{C}$ moved to subgroup B. Besides, subgroup B got six more members and subgroup A was formed. The latter includes only one participant but the very fact that a new category needed to be created is of great importance and registers a significant shift within such a short period.

In the control group changes to the groupings were also noted. The number of students in subgroup $D$ decreased from six to two members alongside an increase in the number of students in subgroup B (from one to six). Subgroup C is characterised by the internal gradational subdivision of its members in spite of the fact that only one member joined the group.

Reviewing the data, we register the following results: (1) for the experimental group, $72.5 \%$ subgroup C; $25 \%$ subgroup $B ; 2.5 \%$ in subgroup A; (2) for the control group $5 \%$ subgroup D; $80 \%$ subgroup C; $15 \%$ in subgroup B.

It's necessary to mention that the majority of students in the experimental group formed two upper (51-60 and 61-70) sublayers in subgroup B while the majority of students in the control group formed two lower (31-40 and 41-50) sublayers in subgroup B.

\section{Post-Study Questionnaire}

After the end of the learning session, all participants were asked to fill in a questionnaire, which is, in essence, a self-evaluation of the results they achieved and an assessment of the tasks they carried out. The main objective of the post-study questionnaire is to receive the participants' feedback that can serve as a 
Table 1

Overall performance on the W-GCTA (experimental group)

\begin{tabular}{llllllllll}
\hline $0-10$ & $11-20$ & $21-30$ & $31-40$ & $41-50$ & $51-60$ & $61-70$ & $71-80$ & $81-90$ & $91-100$ \\
\hline $\mathrm{E}$ & $\mathrm{D}$ & & $\mathrm{C}$ & & & & $\mathrm{B}$ & $\mathrm{A}$ \\
\hline & 1 & 1 & 9 & 8 & 8 & 9 & 3 & 1 & \\
\hline
\end{tabular}

Table 2

Overall performance on the W-GCTA (control group)

\begin{tabular}{llllllllll}
\hline $0-10$ & $11-20$ & $21-30$ & $31-40$ & $41-50$ & $51-60$ & $61-70$ & $71-80$ & $81-90$ & $91-100$ \\
\hline $\mathrm{E}$ & $\mathrm{D}$ & & $\mathrm{C}$ & & & & $\mathrm{B}$ & $\mathrm{A}$ & \\
\hline & 3 & 3 & 10 & 6 & 8 & 9 & 1 & & \\
\hline
\end{tabular}

Table 3

Overall performance on the W-GCTA (experimental group)

\begin{tabular}{llllllllll}
\hline $0-10$ & $11-20$ & $21-30$ & $31-40$ & $41-50$ & $51-60$ & $61-70$ & $71-80$ & $81-90$ & $91-100$ \\
\hline E & D & & C & & & & B & A \\
\hline & & 1 & 6 & 8 & 14 & 7 & 3 & 1 \\
\hline
\end{tabular}

Table 4

Overall performance on the $W$-GCTA (experimental group)

\begin{tabular}{llllllllll}
\hline $0-10$ & $11-20$ & $21-30$ & $31-40$ & $41-50$ & $51-60$ & $61-70$ & $71-80$ & $81-90$ & $91-100$ \\
\hline $\mathrm{E}$ & $\mathrm{D}$ & & $\mathrm{C}$ & & & & $\mathrm{B}$ & $\mathrm{A}$ & \\
\hline & 1 & 1 & 3 & 11 & 9 & 9 & 5 & 1 & \\
\hline
\end{tabular}

basis for further research and for methodological, as well as for the implementation of this approach into teaching practice.

The analysis of the students' responses generated the following results. The question about the influence of the course on a student's development of HOTS received 5 negative answers and 7 'no opinion' answers. Among the positive responses there were 23 'strongly agree' and 45 'agree'. Comments were provided by only 32 respondents. The general trend emerging from the comments was that in the beginning, students found it difficult to do all the cognitive operations, but in the course of study it became easier and more interesting. We can conclude that in mastering LOTS, students increased their HOTS techniques.

The second question targeted students' assessment of their disposition towards working with a literary text. 70 students gave positive answers (19 'strongly agree' and 51 'agree'), 7 participants answered in the negative, and 3 expressed doubt by marking 'no opinion' column. 46 students commented upon the influence of the tasks on their attitude about literary texts. They emphasized that going beyond the surface of a text and extracting information hidden between the lines appealed to them over the course. Again, in our view, this tendency is linked with pre-developed LOTS which enable all the cognitive resources to be directed towards HOTS implementation; this interpretation is directly proven by the responses given to the third question. The correlation between the answers was similar to those given to the second question: 18 'strongly agree', 52 'agree', 8 'strongly disagree' and 'disagree', and 2 'no opinion'.

We designed the fourth and fifth questions to test whether the students deemed the tasks aimed at the development of HOTS to be effective enough. Responding to the fourth question, 5 students had no opinion on the matter, 6 expressed a negative response, and 69 participants answered in the affirmative (21 'strongly agree' and 48 'agree'). The fifth question yielded partially unexpected results: the number of those who disagreed or were in doubt sharply decreased from 6 to 1 'strongly disagree', with 1 'disagree', and from 5 to 1 'no opinion'. Thus, the number of positive responses increased from 21 to 24 'strongly agree' and from 48 to 53 'agree' answers. In the comments provided by 63 respondents, participants noted that things that were vague or 
Table 2

Post-Study Questionnaire

\begin{tabular}{|c|c|c|c|c|}
\hline $\begin{array}{l}\text { strongly } \\
\text { disagree }\end{array}$ & disagree & agree & $\begin{array}{l}\text { strongly } \\
\text { agree }\end{array}$ & $\begin{array}{l}\text { no opinion } / \\
\text { not } \\
\text { applicable }\end{array}$ \\
\hline
\end{tabular}

\begin{abstract}
1. In taking this course, I substantially increased my thinking skills such as: analysing, evaluating, and creating
\end{abstract}

Comments:

2. The tasks fostered my interest in the literary texts

Comments:

3. Having intensive practice in such skills as remembering and applying helped me to better "read between the lines", understand difficult concepts and complex ideas later

Comments:

4. The class discussions enhanced my understanding of the characters, their motifs, symbols writers planted in the text

Comments:

5. The tasks were designed in such a way that encouraged questions and the consideration of different viewpoints.

Comments:

6 . The course affected my attitude towards some controversial issues

Comments:

7. I find this course particularly thoughtprovoking and useful

Comments:

8. Please use the space on the right for any additional comments you wish to make concerning the course 
obscure in the beginning became clearer towards the end in an inexplicable way to them. It was unexpected for the students that the same action of a character or a symbol could give birth to different reasoned opinions.

The sixth statement was designed to establish the way a student's frame of reference may change through the discussion of different viewpoints. In response to this question, we received 4 negative answers, one of which was 'no opinion', and 76 positive answers (20 'strongly agree' and 56 'agree'). 41 students left their comments blank. Some found it surprising that they could study the same issue from different perspectives including that of a character or of their partner.

The seventh question focused on students' overall impressions of the course and its level of usefulness. Surprisingly, despite the presence of both positive and negative answers to other questions, 95\% of the participants found the tasks particularly thoughtprovoking and useful. In their comments, the majority of students stated that in spite of their unwillingness in some cases to do the tasks (tiredness, bad mood, extra-curricular activities), in the course of their work they realized that these were so engaging that they forgot about extraneous factors and wanted to continue working.

To collect additional feedback from students, the eighth question was introduced. The key ideas voiced by the students were: (1) reading stories about hot social issues, such as ethnic and religious factors in policultural societies, gender relationships in postindustrial world, etc.; (2) reading not only books of British and American writers, but also of Indian, Australian and other English-speaking writers; (3) using films instead of books as a basis for the lessons; (4) designing a separate course devoted to studying literature; (5) having debates concerning the key issues after finishing reading a book.

\section{Discussion and Conclusion}

The first hypothesis formulated at the beginning of the third stage was confirmed. The results obtained during the study and post-study interview indicate that the level of critical thinking and sophisticated thinking in general increased among the students in both groups. However, the shift in the control group was not as significant as in the experimental one; this, in turn, confirms our second hypothesis.

The last stage of the project also showed that the students did not try to copy someone else's ideas and thoughts (as we earlier pointed out they did during the first and second stages), but relied more on their own views and opinions formed while working with a text, as well as from their background experience.

The results can also serve as evidence that the students from the experimental group were willing to work with different information irrespective of its content, as it is the very processes of extracting meaning or hidden information from different sources that appeals to them most. While the students of the control group are more inclined to focus on the information per se, the content of which is interesting for them. Thus, we can speculate that the students take less interest in the very process of thinking preferring to deal with new information. In other words, the opposition "interesting vs. not interesting" is the key determinant of their attitude towards information, of whether they want to work with it or not. Consequently, the development of sophisticated thinking should start with the development of disposition towards both the thinking process and processed information.

The project and its results unexpectedly called our attention to the link between well-developed HOTS and one's frame of reference. We can suppose that the development of HOTS enables one's frame of reference to expand and become more flexible. This conclusion was drawn from the students' response to question six in the post-study questionnaire: 76 out of 80 students agreed that the course affected their attitude towards some controversial issues. This finding requires further analysis as it can have a dramatic influence on the selection of methods for sophisticated thinking development. The possible change of frame of reference can also have an impact on the way a person perceives the socio-cultural norms and enables or hinders (it is yet to be determined) the way a person adapts to their community. This may affect teachers and their approach to the texts they are planning to work with in class.

Although the results of our experiment doubtless need further study to be verified, at present they may play a crucial role in theorizing the development of sophisticated thinking. The conclusions based on the results derived from this project propose a theoretical and practical framework of thinking skills development. The triad that was tested through the course of the experiment (disposition -> LOTS -> HOTS) seems, so far, to be the optimum way of enhancing sophisticated thinking.

\section{References}

Barthelme, D. (2003). Sixty stories. London, UK: Penguin Classics.

Binkley, M., Erstad, O., Herman, J., Raizen, S., Ripley, 
M., Miller-Ricci, M., \& Rumble, M. (2012). Defining twenty-first century skills. In P. Griffin, B. McGaw \& E. Care (Eds.), Assessment and Teaching of 21st Century Skills (pp. 17-67). London, UK: Springer.

Cranton, P. (1994). Understnding and promoting transformative learning: A guide for educators of adults. San Francisco, CA: Jossey-Bass.

Grisham, J. (2006). The pelican brief. New York, NY: Delta trade paperbacks.

Halpern, D. F. (2003). Thought and knowledge: An introduction to critical thinking. Mahwah, NJ: Lawrence Erlbaum Associates.

Imel, S. (1998). Transformative learning in adulthood. Retrieved from http://files.eric.ed.gov/fulltext/ ED423426.pdf

Kitchenham, A. (2008). The evolution of John Mezirow's transformative learning theory. Journal of Transformative Education, 6(2), 104-123. doi: $10.1177 / 1541344608322678$

Krathwohl, D. (2002). A revision of Bloom's taxonomy: An overview. Theory into Practice, 41(4), 212-218.

Lemov, D. (2010). Teach like a champion: 49 techniques that put students on the path to college $(K-12)$. San Francisco, CA: Jossey-Bass Teacher.

Luberda, J. (1998). Literary language and complex literature (Unpublished Master's thesis), Northwest Missouri state university, Missouri.

Mezirow, J. (1998). On critical reflection. Adult Learning Quartely, 48(3), 185-198.
Munro, A. (2005). Runaway. London, UK: Vintage Books.

Presseisen, B. Z. (2001). Thinking skills: Meaning and models revisited. In A. L. Costa (Ed.), Developing minds: A resource book for teaching thinking (pp. 4753). Alexandria, VA: ASCD.

Richardson, S. (2013). Using graphic organisers to help students process written texts. Retrieved from http:// www.cambridgeenglishteacher.org/resourcedetails/1209

Taylor, E. W. (1998). The theory and practice of transformative learning: A critical review. Retrieved from http://files.eric.ed.gov/fulltext/ED423422.pdf

Tikhonova, E. V., Kudinova, N. A., \& Golubovskaya, E. A. (2015). Sophisticated thinking: Text, task and situation. In Proceedings of the 9th International Technology, Education and Development Conference (pp. 5461-5470). Madrid, Spain: IATED.

Tikhonova, E., \& Kudinova, N. (2015). Sophisticated thinking: Lower order thinking skills. In Proceedings of the 2nd International Multidisciplinary Scientific Conferences on Social Sciences and Arts (Vol. 2, Book 1.Psychology \& Psychiatry, Sociology \& Healthcare, Education, pp. 911-918). Albena, Bulgaria: STEF92 Technology Ltd. doi: 10.5593/sgemsocial2015/b12/ s3.117

Watson, G., \& Edward, M. (2012). Watson-Glaser critical thinking appraisal user-guide and technical manual. San Antonio, TX: Pearson Education. 
Appendix A

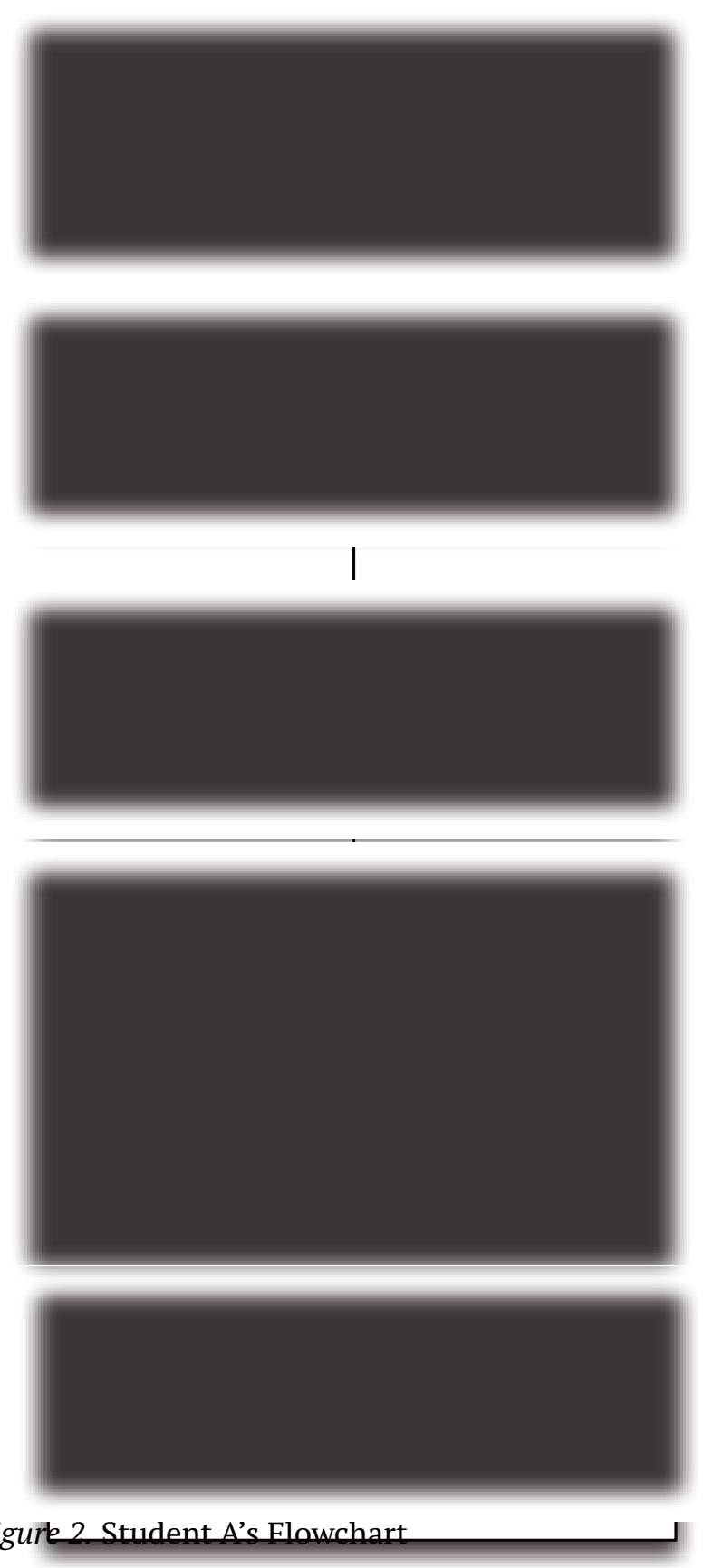

Figure 2. Student A’s Flowchart.

\section{Appendix B}

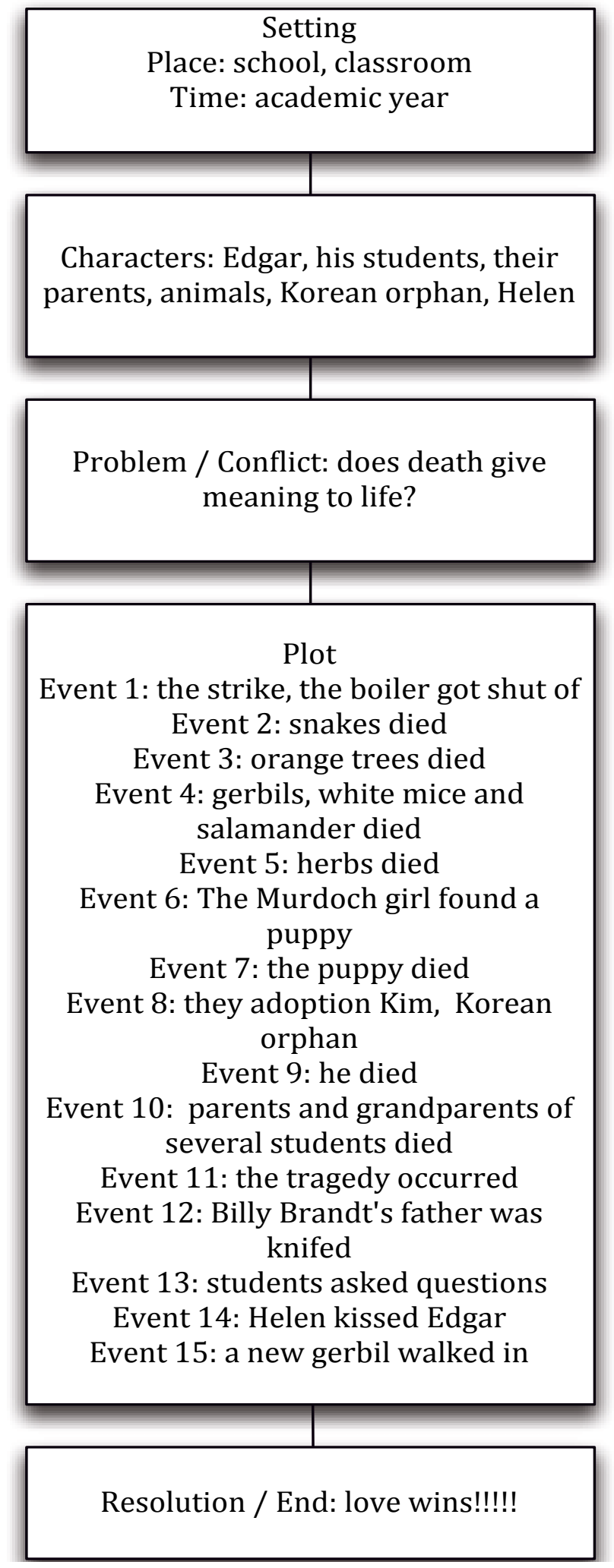

Figure 3. Student B's Flowchart. 